UNIVERSIDADE DE BRASÍLIA-UNB

FACULDADE DE ECONOMIA, ADMINISTRAÇÃO, CONTABILIDADE E CIÊNCIA DA INFORMAÇÃO E DOCUMENTAÇÃO (FACE)

JOSÉ FERNANDO DE SOUZA

\title{
ATITUDES FRENTE À MUDANÇA ORGANIZACIONAL EM UMA INSTITUIÇÃO DO JUDICIÁRIO
}




\title{
José FERNANDo DE SOUZA
}

\section{ATITUDES FRENTE À MUDANÇA ORGANIZACIONAL EM UMA INSTITUIÇÃO DO JUDICIÁRIO}

\author{
Monografia apresentada ao Programa de Pós-Graduação, da \\ Faculdade de Economia, Administração, Contabilidade e \\ Ciência da Informação e Documentação (FACE), da \\ Universidade de Brasília, como requisito parcial à obtenção do \\ grau de Especialista em Gestão Judiciária.
}

Orientadora: Prof ${ }^{a}$. Dra. Maria de Fátima Bruno-Faria

Brasília - DF 


\section{AGRADECIMENTOS}

À toda minha família, pelo apoio irrestrito nas dificuldades e na compreensão para os momentos ausentes, em especial a Jane, Fernanda e Lucas.

À professora Fátima Bruno, pela cordialidade e profissionalismo traduzidos em orientações objetivas e pertinentes, que se mostraram norteadoras do êxito deste trabalho.

Aos professores do curso, que nos dotaram de conhecimento suficiente para o alcance dos objetivos presentes, em especial, ao professor. Marcus Vinícius pela cordialidade dispensada e uma coordenação eficiente.

Aos colegas de curso, pela experiência agradável de dividirmos uma parte de nossas vidas em função de algo tão importante para o ser humano. Em especial a Edson, Gilberto, Aparecida, Hermínia e Ana Lúcia. Juntos fomos capazes de superar muitas dificuldades.

À professora Mírian, pela participação em fase decisiva, que muito acrescentou ao resultado final.

A todos os colegas da instituição que contribuíram de alguma forma para o êxito deste trabalho. 


\section{RESUMO}

No contexto do comportamento organizacional as atitudes dos indivíduos se mostram como um importante fator de análise da predisposição de comportamentos, principalmente no que diz respeito à implantação de mudanças organizacionais. As atitudes positivas frente à mudança estariam ligadas a maior possibilidade de envolvimento adaptação e sucesso, enquanto que as atitudes negativas estariam relacionadas a possíveis comportamentos resistentes levando conseqüentemente ao insucesso. A organização pesquisada apresentou características ambíguas por desenvolver atitudes de temor e aceitação à mudança ao mesmo tempo, o que a credencia como um potencial para resistência, ao mesmo tempo em que apresenta um potencial de não comprometimento. Outra característica importante foi heterogeneidade das respostas traduzidas em dados dispersos e distribuição com características de baixo padrão de normalidade, o que inviabiliza a estimativa segura da probabilidade dos eventos se repetirem no futuro, aspectos que talvez pudessem ser explicados pelo grau de estabilidade das atitudes no processo cognitivo humano.

Palavras-chave: atitude; atitude frente à mudança; mudança organizacional; comportamento organizacional. 


\section{LISTA DE QUADROS}

Quadro 1: Definições teóricas sobre mudança organizacional............................................13

\section{LISTA DE GRÁFICOS}

Gráfico 1: Médias das atitudes do grupo geral e subgrupos. 


\section{LISTA DE TABELAS}

Tabela 1: Composição da amostra.

Tabela 2: Médias e desvios padrão dos fatores de atitudes frente à mudança do Grupo

Geral e Subgrupos.

Tabela 3: Médias e desvios padrão da percepção dos servidores quanto a influência

da Presidência da organização nos processos de mudança .28

Tabela 4: Correlações de Pearson significativas para o fator Ceticismo.

Tabela 5: Coeficientes de correlação e determinação para a relação do Grupo

Geral para o fator Ceticismo e a variável idade do servidor.

Tabela 6: Análise da variância da relação do grupo Geral para o fator Ceticismo e a variável idade do servidor. 30

Tabela 7: Correlações de Pearson significativas para o fator Temor 30 


\section{SUMÁRIO}

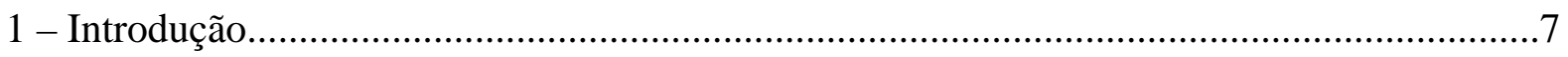

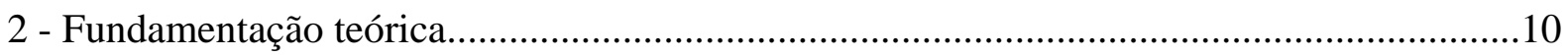

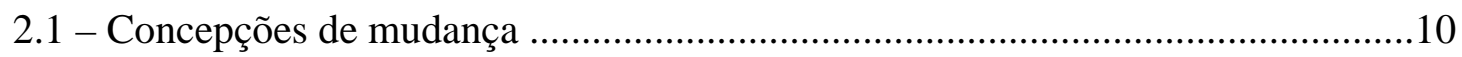

2.1 - Conceito de mudança organizacional................................................................11

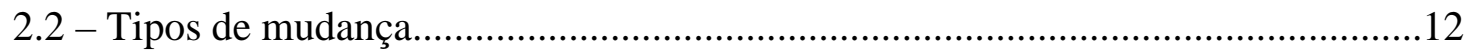

2.3 - Modelos teóricos de mudança organizacional...................................................14

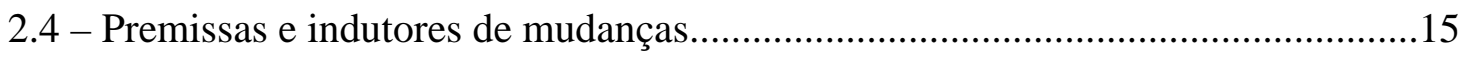

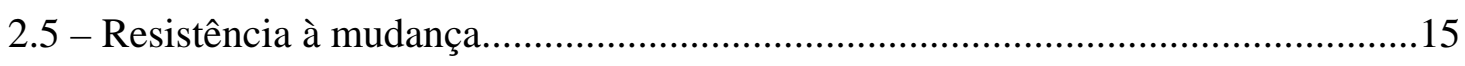

2.6 - Avaliação da mudança organizacional...........................................................18

2.7 - Mudança organizacional no setor público............................................................19

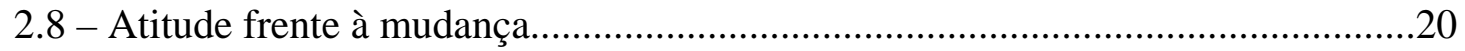

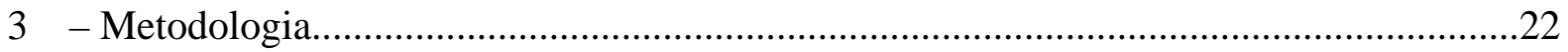

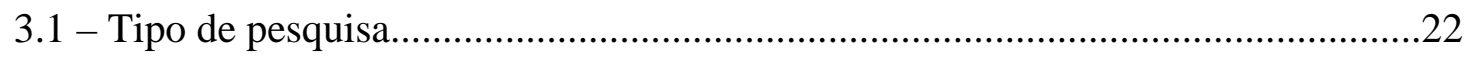

3.2 - Caracterização da organização....................................................................22

3.3 - População e amostra.......................................................................................23

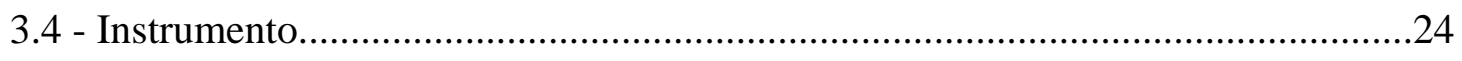

3.5 - Procedimentos de coleta de dados...................................................................24

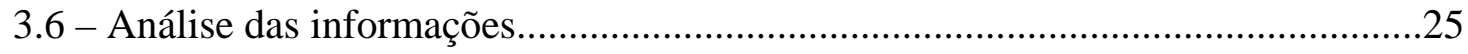

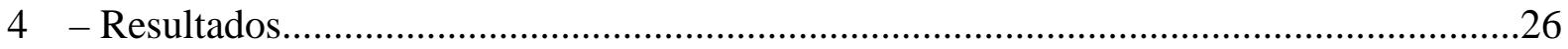

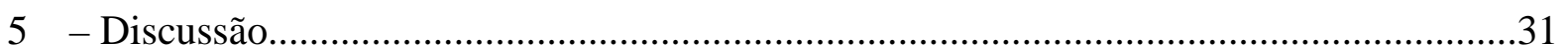

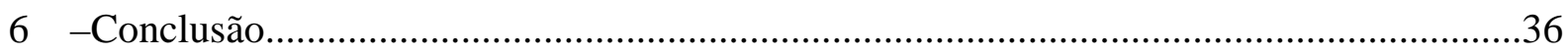

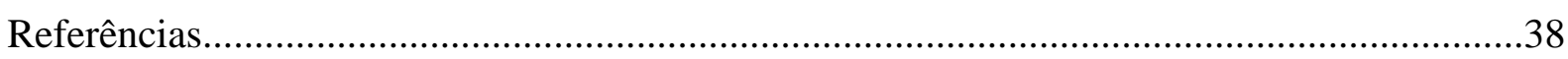

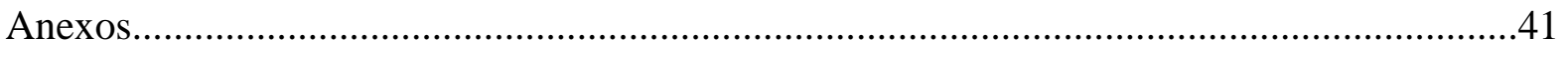

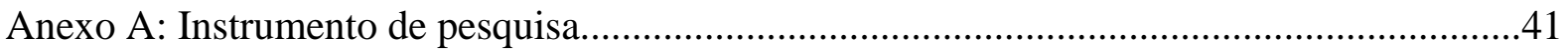




\section{1 - INTRODUÇÃO}

Para Renault (2005) alguns dos principais problemas do Judiciário brasileiro são: morosidade, obsolescência, ineficiência e pouca transparência da máquina pública a serviço do judiciário. Segundo o autor há no Brasil um processo em tramitação para cada sete habitantes e que isto não significa que a população exerce efetivamente o direito de recorrer a justiça, o que ocorre é uma grande concentração de processos de interesse de grandes empresas e das três esferas de governo, federal, estadual e municipal. Acrescenta que não há apenas um poder judiciário, na verdade são vários: a Justiça Federal, a Justiça comum dos Estados e Federação, além das especializadas (militar, trabalhista e eleitoral), as instâncias superiores e os juizados especiais perfazendo ao todo 91 tribunais relativamente autônomos quanto a sua administração e com pouca interligação entre si.

A Emenda Constitucional número 45, (BRASIL, 2006) como fruto de uma longa discussão sobre o judiciário brasileiro, apresentou inovações objetivando diminuir os problemas apresentados, desta forma o controle externo exercido pelo Conselho Nacional de Justiça, que tem como principal atribuição o planejamento e implementação de políticas judiciais, é fundamental para um judiciário mais transparente, célere e com algum tipo de controle, sem retirar a autonomia e independência das decisões dos magistrados. A importância destas alterações está na possibilidade de promover a integração de programas de informatização, qualificação de servidores e a gestão administrativa para todo o sistema o que deverá acarretar maior acessibilidade e celeridade.

Dentro desta nova perspectiva, o estudo do funcionamento destas instituições, de suas características culturais e comportamentais, subsidiará o planejamento de ações que almejem alcançar os objetivos estabelecidos nas novas políticas judiciais. Depreende deste raciocínio a ocorrência de processos de mudanças no âmbito destas instituições, destacando-se a importância do entendimento da atitude do corpo funcional frente a um processo de mudança.

A mudança organizacional é um tema bastante complexo, de difícil análise e de fundamental importância para as organizações, pois tem reflexo direto no desempenho dos funcionários e conseqüentemente nos resultados de uma organização. Segundo Grey (2004) haveria o entendimento de se observar a mudança organizacional, muitas vezes, como requisito para a sobrevivência da organização:

Praticamente todos os estudiosos de organizações, executivos e estudantes de administração parecem persuadidos pela idéia de que vivemos tempos de mudanças sem precedentes, de que a sobrevivência organizacional depende da mudança e que o trabalho dos executivos gira em torno da mudança.(GREY, 2004, p.11) 
Seabra (2001) defende que para uma organização sobreviver, em ambientes cada vez mais competitivos, deve estar atenta às mudanças no ambiente externo. Considerando que um processo de mudança ocorre influenciado por fatores externos e internos a uma organização, esses aspectos devem ser abordados em uma análise mais profunda sobre o tema.

O judiciário nacional apresenta-se inexplorado, quanto a esse aspecto, pelos estudos científicos. Na literatura nacional, os estudos referentes à mudança organizacional em instituições públicas, dos poucos encontrados, estão na sua maioria ligados ao poder executivo. Embora possa apresentar semelhanças, principalmente por ter funcionários públicos estáveis, em muito diferem no produto final, ou seja, o cliente do judiciário demanda um tipo de serviço diferenciado. Ocorre que a produção científica sobre o tema tem como base o comportamento das instituições privadas, o que desafia a tentar identificar semelhanças e diferenças no comportamento preconizado pela teoria. Para Feuerschütter (1997), grande parte dos estudos, até então, eram influenciados pela orientação mecanicista que destacava a tecnologia, a estrutura e o tamanho da organização. Leitão e Rossi (2000) apontam que os processos de mudança no mundo ocidental adotam tecnologia como instrumento de dominação da natureza e que a associação desta com o capital viria a tratar de forma dura o trabalho, o que em suma considera o trabalhador como fator de produção, descartável.

Outro aspecto importante e que talvez faça a ligação entre a esfera pública e a privada, no tocante ao tema mudança organizacional, é que o objeto em estudo é o ser humano, seu comportamento e sua subjetividade, individual e grupal, frente a um processo que ocorre em ambos, mesmo que com especificidades distintas, porém com dinâmica semelhante em muitos aspectos. Leitão e Rossi (2000) acrescentam, que com base no conhecimento disponível, seria impossível rejeitar a subjetividade no funcionamento da percepção humana, pois seria passagem obrigatória para o pensar/agir, sendo fator imprescindível para o entendimento de uma organização.

Uma particularidade relevante a ser destacada é que judiciário não sofre processos de concorrência, nem é sujeito às leis de oferta e demanda, não visa lucro nem pode demitir funcionários em processos de mudança. Isso não significa que não sofra pressões para prestação de serviço com qualidade e com o menor custo para a sociedade que o mantém, e que essas organizações não busquem legitimação frente à sociedade. O que acontece no judiciário exige uma forma diferente de introduzir e gerenciar as mudanças necessárias para o cumprimento de sua missão. Não foram identificados, na literatura nacional, estudos acadêmicos que analisem estes aspectos, o que se revela como um universo pouco conhecido 
para a academia, bem como a possibilidade de se apresentar os primórdios para o entendimento de uma lacuna no estudo da mudança organizacional.

A contribuição prática desse trabalho seria a obtenção de dados, que facilitariam a ação administrativa e a tomada de decisão por parte dos dirigentes do judiciário, uma vez que melhor compreenderiam as possibilidades de comportamento da instituição, através do entendimento da atitude dos funcionários frente à implementação de mudanças. 


\section{2 - FUNDAMENTAÇÃO TEÓRICA}

A mudança organizacional é um tema bastante discutido no âmbito das organizações numa busca pelo conhecimento e compreensão do comportamento humano no ambiente organizacional. Assim, por envolver o comportamento humano, apresenta uma complexidade e aspectos difíceis de serem compreendidos. Para Leitão e Rossi (2000) é inaceitável considerar a mudança organizacional como um problema técnico, pois se trata de algo complexo, inter e transdisciplinar adentrando em campos da filosofia e da ideologia. Para os autores, a preocupação dominante é prescrever antes de descrever ou explicar o fenômeno da mudança, e que o Brasil adota acriticamente a forma americana de gerir a mudança o que tornam o tecnicismo e a modelagem como formas dominantes de entender e propor mudanças e que isto dificulta o entendimento do processo.

Neste capitulo, serão abordadas as concepções da mudança, onde será feita uma análise na origem do pensamento filosófico sobre o tema. Em seguida, discutida a conceituação de mudança segundo autores nacionais. Relevante, também, observar a tipificação da mudança por tratar-se de um evento importante para o presente estudo. A exposição de modelos teóricos que buscam explicar processos de mudança, bem como as premissas e indutores de mudança em uma organização se fazem presentes, objetivando fornecer uma visão abrangente sobre o tema. O fenômeno da resistência e o gerenciamento da mudança serão discutidos, assim como, alguns métodos para a avaliação da mudança. Por fim, será abordado o tema no âmbito das organizações públicas.

\section{1 - Concepções de mudança}

Leitão e Rousseau (2004) consideram que, para o entendimento da mudança, é necessário compreender a natureza do conhecimento que se tem do mundo em geral e do mundo da administração. Leitão e Rossi (2000) descrevem os primórdios das concepções sobre a mudança da seguinte forma: para Platão, como para Aristóteles o termo mudança significa movimento, ou seja, significa tornar-se outra coisa, a passagem de um modo de ser a outro. Apontam a existência de um substrato que se conserva invariável no seu estado inicial e final. Destacam que na filosofia escolástica admitia-se a possibilidade da mudança substancial, ou mutação, quando a própria essência transformava-se em outra e a mudança acidental, quando a substância não é afetada, observando nesse tipo a mudança quantitativa e qualitativa, nessa quando ocorre mudança na forma exterior e naquela quando ocorre o 
aumento ou diminuição da coisa que muda. Prosseguem que no Tomismo a mudança significava ir de uma causa à outra infinitamente numa sucessão lógica e com uma determinada ordem linear ou cíclica e/ou incompleta. Abordam também concepções de mudança na observação de fenômenos naturais relacionados com a Biologia, Física e Química. Analisam a visão da teoria da autopoiese de Humberto Maturana e Francisco Varela, onde todo ser vivo passa por mudanças contínuas estruturais, enquanto preserva seu padrão de organização semelhante a uma teia. Embora esta teoria tenha trazido uma nova compreensão da mudança não pode ser aplicada à vida social. Alegam a existência de autores que afirmam a necessidade dos gerentes pensarem as organizações como organismos vivos, entre eles Peter Senge.

Seabra (2001) aponta, também, os defensores da teoria dos sistemas que afirmam que as organizações, assim como os organismos vivos, são compostos por subsistemas que interagem entre si e com o ambiente externo. Continuando na análise, Leitão e Rossi (2000) apresentam que a primeira percepção do fenômeno mudança seria decorrente do movimento de rotação e translação do planeta que dá origem aos dias e às estações. Essas mudanças trazem a noção de tempo cíclico, descontínuo e qualitativo em contraposição com o tempo linear, contínuo e quantitativo marcado pelo relógio das sociedades industriais. Para os autores, as duas noções de tempo/mudança estão presentes na vida humana, tendo as organizações se afastado do conceito natural. Acrescentam que o hábito de fragmentar a realidade levou à separação do ambiente organizacional do ambiente natural e à sociedade total incluída neste. O que explica hoje o discurso da adaptação das organizações ao ambiente.

\section{2 - Conceito de mudança organizacional}

Para Neiva e Paz (2007), do ponto de vista científico, pouco se sabe sobre o processo de mudança organizacional. Segundo Van de Vem e Poole (1995 apud LEITÃO; ROSSI, 2000), os modelos e teorias não avançaram o suficiente para o entendimento sobre o processo e a seqüência de eventos de uma mudança organizacional. Para Feuerschütter (1997) grande parte dos estudos sobre mudança organizacional se desenvolve sobre orientação de paradigmas mecanicistas e que muitas das discussões se baseiam em perspectivas do indivíduo e do seu comportamento, não levando em conta os componentes simbólicos e as interações que fundamentam a realidade das organizações.

Lima e Bressan (2003) destacam que poucos textos científicos se preocupam em definir o conceito de mudança organizacional devido à dificuldade de delimitar seus limites, 
além dos vários níveis de abordagem. Neiva e Paz (2007) apontam que muitos são os aspectos considerados na definição do conceito de mudança organizacional, entre eles, o escopo, intensidade, tempo de reação, pessoas envolvidas. Lima e Bressan (2003), no estudo sobre a conceituação de mudança organizacional, apontam para a convergência, de autores ligados ao tema, em torno das seguintes dimensões: intencionalidade, transformação/congruência sistêmica entre componentes, relevância do impacto da mudança, resposta ao ambiente, temporalidade, construção social da mudança e resposta à demanda interna como dimensões relevantes a serem consideradas para a compreensão e a definição de um conceito de mudança. Dessa forma, as autoras apresentam o seguinte conceito:

\footnotetext{
Mudança organizacional é qualquer alteração, planejada ou não, nos componentes organizacionais - pessoas, trabalho, estrutura formal, cultura ou nas relações entre a organização e seu ambiente, que possam ter conseqüências relevantes, de natureza positiva ou negativa, para a eficiência e/ou sustentabilidade organizacional. (LIMA; BRESSAN, 2003, p. 25)
}

Com o objetivo de esclarecer a diferença entre mudança organizacional e processos de criatividade e inovação, Bruno-Faria (2003) apresenta uma definição sobre o tema, obtida de uma síntese do que seria mais comum nas diversas definições encontradas na literatura e aprimorada pela a observação da autora:

\begin{abstract}
Mudança organizacional é qualquer alteração, planejada ou não, ocorrida na organização, decorrente de fatores internos e/ou externos à mesma, e que tenha algum impacto nos resultados e/ou nas relações entre as pessoas no trabalho. (BRUNO-FARIA, 2003, p. 128)
\end{abstract}

A autora ressalta que essa definição engloba aspectos como o fato da mudança ser planejada ou não, fatores internos e externos à organização como indutores e os impactos nos resultados e nas relações interpessoais no trabalho, além da possibilidade de resultados negativos para os objetivos da organização.

\title{
2.3 - Tipos de mudança
}

Neiva e Paz (2007) e Lima e Bressan (2003) convergem no entendimento de que além da definição, existe ainda a dificuldade quanto à tipologia da mudança, levando-se em conta a necessidade de se especificar qual tipo, objeto ou conteúdo da mudança mencionada. Para tipificação da mudança é necessário delimitar com clareza o espaço analisado. A literatura sobre o tema apresenta classificações tais como: incremental/organizacional; 
transformacional/institucional; contínua, episódica, $1^{\text {a }}$ ordem; $2^{\text {a }}$ ordem; incremental/contínua; descontínua; convergente e radical, que tentam representar formas de mudança organizacional. Para Greenwood e Hinnings (1996 apud BRUNO-FARIA, 2003) existe a distinção entre mudança convergente e radical, mudança evolucionária e revolucionária, quais são: a radical ocorre com a dissolução da orientação existente com uma transformação organizacional; a convergente acontece de forma paralela à orientação existente; a evolucionária ocorre de forma gradual e lenta; a revolucionária afeta simultaneamente todas as partes da organização com rapidez.

\begin{tabular}{|c|c|c|}
\hline Referência & Tipos de mudança & \\
\hline Silva (1999) & $\begin{array}{l}\text { Incremental/organizacional } \\
\text { Aumento da eficiência e do uso dos } \\
\text { recursos, mudança na arquitetura da } \\
\text { empresa }\end{array}$ & $\begin{array}{l}\text { Transformacional/institucional } \\
\text { Questionamento e mudança da } \\
\text { missão, natureza e objetivo da } \\
\text { organização. }\end{array}$ \\
\hline Weick e Quinn (1999) & $\begin{array}{l}\text { Contínua } \\
\text { Mudança constante, cumulativa e } \\
\text { evolutiva. Podem ser pequenos avanços } \\
\text { que ocorrem cotidianamente em toda } \\
\text { organização, cumo acúmulo pode propiciar } \\
\text { uma mudança significativa na organização. }\end{array}$ & $\begin{array}{l}\text { Episódica } \\
\text { Mudança pouca freqüente, } \\
\text { descontínua e intencional, que } \\
\text { ocorre durante períodos de } \\
\text { divergência, quando as empresas } \\
\text { saem de sua condição de equilíbrio. }\end{array}$ \\
\hline Robbins (1999) & $\begin{array}{l}1^{\text {a }} \text { ordem } \\
\text { Mudança linear e contínua. Não implica em } \\
\text { mudanças fundamentais nas pressuposições } \\
\text { dos funcionários sobre o ambiente e sobre } \\
\text { aspectos que podem causar melhorias na } \\
\text { empresa. }\end{array}$ & $\begin{array}{l}2^{\mathrm{a}} \text { ordem } \\
\text { Mudança multidimensional, } \\
\text { multinível, descontínua e radical, } \\
\text { que envolve reenquadramento de } \\
\text { pressupostos sobre a empresa e o } \\
\text { ambiente em que ela se insere. }\end{array}$ \\
\hline Nadler et.all (1994) & $\begin{array}{l}\text { Incremental/continua } \\
\text { Continuidade do padrão existente. Pode ter } \\
\text { dimensões diferentes, mas é realizada } \\
\text { dentro do contexto atual da empresa. }\end{array}$ & $\begin{array}{l}\text { Descontínua } \\
\text { Mudança do padrão existente, que } \\
\text { ocorre em períodos de desequilíbrio } \\
\text { e envolve uma ou várias } \\
\text { reestruturações de características da } \\
\text { empresa. }\end{array}$ \\
\hline $\begin{array}{lll}\text { Porras } & \text { e } & \text { Robertson } \\
(1992) & & \end{array}$ & $\begin{array}{l}1^{\text {a }} \text { ordem } \\
\text { É uma mudança linear e contínua, que } \\
\text { envolve alterações nas características dos } \\
\text { sistemas, sem causar quebras em aspectos- } \\
\text { chave para a organização. }\end{array}$ & $\begin{array}{l}2^{\mathrm{a}} \text { ordem } \\
\text { É uma mudança multidimensional, } \\
\text { multinível, radical e descontínua, } \\
\text { que envolve quebra de paradigmas } \\
\text { organizacionais. }\end{array}$ \\
\hline $\begin{array}{l}\text { Greenwood e Hinings } \\
\text { (1996) }\end{array}$ & $\begin{array}{l}\text { Convergente } \\
\text { Ajuste fino na orientação organizacional } \\
\text { existente }\end{array}$ & $\begin{array}{l}\text { Radical } \\
\text { Ruptura com a orientação existente e } \\
\text { transformação da organização. }\end{array}$ \\
\hline
\end{tabular}

Quadro. 1 - Definições teóricas sobre mudança organizacional

Fonte: Lima e Bressan (2003, p.23)

Lima e Bressan (2003) acrescentam que os tipos de mudança acima apresentados são muito similares e que se caracterizam por duas formas principais de mudanças, ainda que adotando nomenclaturas diferentes, onde a primeira altera apenas aspectos da organização, que seriam pequenos ajustes que ocorrem em ambientes mais estáveis, e a segunda trata da mudança que envolve rupturas de padrões anteriores e engloba toda a organização em razão de grandes alterações em seu ambiente. Corroborando com esse pensamento, Bruno-Faria (2003), no mesmo sentido, aponta a necessidade da definição ou distinção dos tipos de 
mudança, sendo que o mais comum é o tipo que aprimora a organização sem alterar a orientação existente, além do denominado tipo radical que rompe com o passado. Para Fernandes e Zanelli (2006), o processo de mudança torna-se mais complexo quando envolve a razão de ser da organização, pois esta envolveria muito mais do que aprendizagem de uma nova forma de execução do trabalho, bem como a formação de uma nova cultura, o que se assemelha à mudança radical.

\section{4 - Modelos teóricos de mudança organizacional}

Segundo Grey (2004) e Lima e Bressan (2003) o modelo mais utilizado para explicar o processo de mudança é o modelo de Lewin que apresenta como premissa básica a existência de um equilíbrio entre as forças que mantêm a situação estável, estas forças antagônicas, algumas opostas à mudança e outras favoráveis. Assim a mudança era concebida quando se aumentavam as forças favoráveis, ou quando diminuíam-se as resistências, para Lewin esse processo era visto como uma instabilidade transitória que interrompia o equilíbrio estável de um sistema. Esse modelo aponta três etapas que seriam o descongelamento, mudança ou movimento e o re-congelamento, sendo que no descongelamento seria provocado um desequilíbrio entre as forças normalmente no sentido de diminuir a resistência, ou aproveitando-se de uma insatisfação existente na organização. Na segunda etapa, ocorreria a mudança, que continuaria até que se estabelecesse novo equilíbrio denominado recongelamento. Outro aspecto a ser destacado é que nesta visão mecanicista seria possível gerenciar a mudança de forma a atingir os objetivos.

Outros modelos causais de mudança segundo Neiva e Paz (2007) seriam os de Burke e Litwin, bem como o de Greenwood e Hinings, sendo que o primeiro estabelece conteúdos de mudança e o segundo trata de aspectos relevantes da interação da organização como ambiente. Lima e Bressan (2003) explicam o primeiro modelo como uma relação entre a mudança transformacional que seria influenciada pelo ambiente, missão, estratégia, liderança e cultura organizacional, e a mudança contínua a qual sofre a influência de fatores internos tais como: estrutura organizacional, práticas de gestão, sistemas e políticas, clima de trabalho, tarefas e habilidades, motivação, necessidades e valores.

O segundo modelo, o de Greenwood e Hinnings, no entendimento de Lima e Bressan (2003) e Neiva e Paz (2007), considera as dependências de poder como parte importante do fenômeno. As organizações seriam arenas nas quais coalizões, com diferentes interesses, graus diferenciados de envolvimento com valores preponderantes na organização e 
capacidades de influenciar, tentam dominar grupos insatisfeitos com o grau em que seus interesses estão sendo realizados nas organizações. Dessa forma, conclui que o fenômeno da política é fundamental para a introdução de mudança nas organizações, ou seja, a arena política como antecessora de mudança nas características fundamentais na organização.

\section{5 - Premissas e indutores de mudanças}

Segundo Lima e Bressan (2003), a premissa encontrada na literatura sobre a mudança é a de que essa seria sempre benéfica, embora não se especifique para quem ou para que. Apontam para duas hipóteses que sustentariam a realização de mudanças organizacionais: a primeira seria a existência de uma relação entre mudança e sustentabilidade institucional, baseada na adaptação ao ambiente, e a segunda seria a premissa de eficiência organizacional. Para Wood, Curado e Campos (1995 apud FERNANDES; ZANELLI, 2006), os objetivos mais freqüentes das organizações para justificar processos de mudança são: melhorar a qualidade, aumentar a produtividade, refletir valores dos novos lideres, reduzir custos e administrar conflitos. Para Hernandez e Caldas (2001), as organizações mudam em resposta à competitividade crescente, novas leis ou regulamentações, introdução de novas tecnologias ou para atender variações na preferência de consumidores ou parceiros.

A literatura aponta fatores que podem ser considerados como indutores de mudança em uma organização. De uma forma mais ampla, pode-se apontar aspectos econômicos, tecnológicos, políticos e sociais como sendo os principais influenciadores ou indutores de mudança em uma organização. Alguns autores tentam descrever a forma como se dá essa interação com a organização. Lima e Bressan (2003) alertam para a necessidade de diferenciação entre mudança organizacional e os processos de desenvolvimento, aprendizagem organizacional e cultura organizacional, para que possam ser analisadas as mudanças advindas desses processos dentro de seu contexto específico. Segundo Robbins (2005) seriam seis as forças que atuam estimulando a mudança organizacional, sendo elas: a natureza da força de trabalho, tecnologia, choques econômicos, concorrência, tendências sociais e a política mundial.

\section{6 - Resistência à mudança}

Lima e Bressan (2003) alegam que em qualquer momento, processos de mudança geram incertezas para os empregados, os quais reagem, ou resistem numa tentativa de 
manutenção da identidade, da autonomia e controle sobre a tarefa que era realizada, além do temor da perda de poder ligada ao cargo ocupado. Para Hernandez e Caldas (2001), a literatura acadêmica e gerencial define a resistência como qualquer conduta que objetiva a manter o status quo em face de pressões para modificá-lo. Apontam, ainda, pressupostos tidos como verdades, assim a resistência seria vista como: uma circunstância inevitável; nociva à organização; comportamento natural dos seres humanos; comportamento exclusivo de empregados; fenômeno massificado. Os autores contra-argumentam, e propõem uma abordagem individual para superação dos comportamentos resistentes, onde se levaria em conta aspectos, ou contra-pressupostos, tais como: o surgimento de comportamentos resistentes apenas em circunstâncias excepcionais; que agentes de mudança muitas vezes acabam contribuindo para o agravamento; que a resistência pode ser um comportamento definido pelos detentores de poder quando são desafiados em seus privilégios; que a resistência pode ser um fenômeno saudável e positivo; que os seres humanos anseiam por mudanças o que muitas vezes sobrepõem-se ao medo do desconhecido; que a resistência é um comportamento que pode ser exibido, também, por gerentes e, por fim, que a resistência é um fenômeno tanto individual quanto grupal e que varia de um indivíduo para outro em função de fatores pessoais e situacionais.

Robbins (2005) aponta um aspecto positivo da resistência à mudança das organizações e de seus membros como um fator que garante certo grau de estabilidade e previsibilidade ao comportamento. Aponta a resistência como fonte de conflitos funcionais. Defende que a resistência não se apresenta de forma padronizada podendo ocorrer de forma aberta, imediata, implícita e protelada. Para o autor, a resistência nas formas aberta e/ou imediata são mais facilmente contornadas, ao contrário das ações implícitas e/ou proteladas, nesta última as reações à mudança são mínimas no momento de sua implementação, podendo ocorrer uma reação desproporcional em algumas semanas, meses e até anos após a implementação. As reações viriam à tona na forma de perda de lealdade à organização, motivação, aumento de erros, perda de qualidade e absenteísmo. O autor aponta os hábitos, segurança, fatores econômicos, medo do desconhecido e o processamento seletivo de informações como fontes para o surgimento de resistência nos indivíduos. Já a inércia estrutural, foco limitado de mudança, inércia de grupo, ameaça à especialização, ameaça às relações de poder estabelecidas e ameaça às alocações de recursos estabelecidas como a fonte para a resistência organizacional.

Neiva (2004) aborda a questão da resistência à mudança sob o foco da cognição individual. Aponta que a literatura traz basicamente duas tendências explicativas e que na 
maioria dos estudos nesta área estão implícita ou explicitamente ligados à teoria da dissonância cognitiva de Festinger que sugere que as pessoas buscam diminuir as inconsistências entre as suas atitudes e seu comportamento. A primeira tendência seria segundo George e Jones (2001 apud NEIVA, 2004) o desencadeamento de reações emocionais como resposta às inconsistências e discrepâncias entre esquemas cognitivos concorrentes ativados pelas propostas de mudança, levando a uma configuração favorável à resistência. A segunda tendência segundo Bovey e Hede (2001 apud NEIVA, 2004) enfoca a resistência como uma intenção comportamental.

Segundo Neiva (2004), autores destacam a presença de atitudes opostas, ou seja, atitudes de temor e aceitação frente à mudança, fenômeno denominado de ambigüidade, como uma premissa que antecede o comportamentos de resistência à mudanças. Essa ambigüidade, segundo os autores, não favorece a mudança de comportamento. Para a autora se não houver mudança de comportamento não ocorrerão mudanças em larga escala. A dificuldade ocorreria nas formas de medir a ambigüidade. Uma sugestão apresentada seria a possibilidade de detectar uma postura ambígua em uma organização através das médias apresentadas nos fatores que representam atitudes de temor e aceitação quando forem altas e próximas uma da outra.

Silva e Vergara (2003) destacam que a mudança organizacional, mesmo quando intencional, não deve ser entendida somente sob a ótica de estratégias, processos ou tecnologias, sem levar em consideração a dimensão social como uma variável determinante das possibilidades de sucesso. Hernandes e Caldas (2001) acrescentam que as ações e reações dos indivíduos seriam baseadas na realidade percebida, e não necessariamente, na realidade objetiva e que tão importante quanto a análise das causas da resistência seria a identificação de grupos e indivíduos que terão maior propensão a resistir. Apontam que os indivíduos compartilham diferentes graus de dogmatismo, sendo razoável supor que quanto maior o grau de dogmatismo maior é a possibilidade de comportamento resistente.

Na mesma linha, Fernandes e Zanelli (2006) observam que a identificação com a organização muitas vezes acaba tornando-se uma obrigação para os funcionários, que não mais questionam o que fazem no dia-a-dia das empresas, adotando tão cegamente certos comportamentos que, quando surge a necessidade de mudança, sentem-se vulneráveis, resistindo fortemente, por acreditarem que serão afetados no domínio de seu trabalho. Os autores concebem ainda que, de modo geral, quanto mais estável e homogênea for uma organização mais difícil será a realização de mudanças. 
Para Kolter e Schlesinger (1979 apud HERNANDEZ; CALDAS, 2001), as estratégias para superação de resistência à mudança podem ser descritas como: educação e comunicação; participação e envolvimento; facilitação e suporte; negociação e acordo; manipulação e cooperação; coerção explícita e/ou implícita Já Grey (2004) credita os casos de fracasso apresentado pela adoção das estratégias descritas, por não considerarem a possibilidade da mudança como algo realmente indesejável, e a resistência como evento inevitável e que ao final do processo de uma forma ou de outra levará a um quadro de aceitação. Para Fernandes e Zanelli (2006), o engajamento das pessoas envolvidas no processo de mudança será maior, se forem levados em consideração, por parte dos gestores, os sentimentos, dúvidas, inseguranças, opiniões e percepções dos indivíduos.

\section{7 - Avaliação de mudança organizacional}

Robbins (2005) propôs, adotando três níveis de análise, individual, grupal e organizacional, um modelo básico para o estudo do comportamento organizacional e que no nível individual devem ser arroladas variáveis biográficas, de personalidade, valores, atitudes e habilidades. Siqueira (2002) ao analisar o modelo de Robbins, no âmbito individual, expõe que as variáveis descritas influenciam a tomada de decisão uma vez que afetam o processo de percepção, motivação e aprendizagem. Segundo a autora a análise dos grupo é composta por “interações bidirecionais entre os processos de tomada de decisão grupal, comunicação, liderança, conflito, poder, política, estrutura de grupos e equipes de trabalho” (SIQUEIRA, 2002, p. 14). Robbins (2005) aponta a cultura, política, ações de recursos humanos e tecnologias como variáveis do grupo geral da organização. Por fim o autor aponta a rotatividade, absenteísmo, produtividade e satisfação como prováveis resultados das interações entre todos os três níveis de análise.

Para Neiva (2003), os estudos sobre a avaliação da mudança organizacional não diferenciam, mencionam ou discutem os objetivos ou a amplitude das intervenções realizadas. Acrescenta a autora que no planejamento de uma investigação sobre a mudança devem ser consideradas as características do processo, no âmbito da intervenção, o que demandaria acompanhamento e comparação dos eventos, além da estimação da efetividade.

Carnall (1986 apud NEIVA, 2003) propõe um modelo para avaliação da mudança organizacional que aborda noções de ordem social e das relações coletivas. O modelo interpreta as organizações como ambientes compostos de grupos diferenciados em relação ao poder, status, recompensas, privações e interesses. A pressão pela desestabilização de uma 
ordem estabelecida como resultado de uma relação de troca entre grupos de interesse num determinado tempo e local, revelam novas oportunidades para a reconstrução de uma nova ordem. O modelo focaliza como as pessoas vivenciam e respondem às mudanças. Propõe avaliar o impacto da mudança nas relações de troca, ou seja, avaliar as conseqüências da mudança sobre a vantagem relativa ou a desvantagem percebida pelos membros dos diferentes grupos.

Segundo Carnall (1986 apud NEIVA, 2003), a nova ordem estabelecida é fruto da percepção das pessoas sobre o grau de justiça da situação em comparação com outras pessoas e ao passado, que levaram a aquiescência ou oposição. A comparação é baseada em aspectos tais como: contribuição, eqüidade, reciprocidade, necessidade e adesão ao comprometimento. Como conseqüência a percepção de uma mudança como injusta levará à resistência, ritual, acomodação, modificação, aquiescência, partida e aceitação. Propõe-se verificar como tais fenômenos ocorrem durante a implantação de um processo de um programa de intervenção para mudança.

\section{8 - Mudança organizacional no setor público}

Para Costa e Cavalcanti (1991), as mudanças nas organizações públicas visam, geralmente, alterar a missão, as ações políticas e estratégicas, assim como as formas de gerenciamento e o comportamento de seus integrantes. Pacheco (1988 apud FEUERSCHÜTTER, 1997) sugere uma especial atenção ao arranjo formal das organizações quando ocorrem a entrada de novos administradores nas organizações públicas, pois tais dirigentes estabelecem novos parâmetros para a divisão do trabalho e para a configuração dos níveis hierárquicos buscando o alcance dos resultados prioritários.

As mudanças estruturais, segundo Feuerschütter (1997) são utilizadas como mecanismo estratégico de controle administrativo, que afeta os componentes básicos do arranjo formal da organização, entre os quais estão: as relações de subordinação, distribuição de cargos e tarefas, além da maneira como os indivíduos se relacionam no que tange aos padrões normativos. Aponta, também, a dimensão política como preponderante no delineamento das ações de mudança como viabilizador do processo. Em complemento, a autora aponta que, em momentos de disputa de poder, modificações estruturais são defendidas por se mostrarem como mecanismo de ascensão a posições privilegiadas, acarretando como conseqüência o exercício da influência na tomada de decisões futuras, bem como na alocação de recursos e acesso à rede de informação e comunicação. Afirma ainda, que a mudança 
organizacional pode ocorrer a partir de ações unilaterais exercidas pelos dirigentes, pela substituição de pessoal ou pela mudança na estrutura.

\section{9 - Atitude frente à mudança}

Robbins (2005, p. 60) define atitude como: “afirmações avaliadoras - favoráveis ou desfavoráveis - em relação a objetos, pessoas ou eventos”. Acrescenta que as atitudes refletem o sentimento de um indivíduo em relação a alguma coisa. Para o autor, as atitudes são compostas por três componentes: cognição, afeto e comportamento. A componente cognição se refere à capacidade do indivíduo em estabelecer uma convicção ou uma afirmação avaliadora seja positiva ou negativa. O componente afeto se refere ao sentimento que permite a elaboração de uma predisposição convergente com a convicção estabelecida. O componente comportamental de uma atitude se refere à intenção, ou o que autor chama de consistência, o qual o indivíduo se dispõe a adotar comportamentos condizentes com a convicção estabelecida.

Para Robbins (2005), as atitudes podem levar um indivíduo a um comportamento desejável ou não. Para o autor as atitudes são menos estáveis que os valores e que isso permite serem trabalhadas para evitar comportamentos indesejáveis. Um estudo detalhado das atitudes dos funcionários é de grande importância para os administradores de forma a prever certos comportamentos. Segue, que um indivíduo pode ter diversas atitudes e no campo organizacional uma pessoa satisfeita com seu trabalho tende a ter atitudes positivas em relação à ele e vice-versa. Acrescenta que as pessoas buscam a consistência entre a atitude e o comportamento, ou seja, as pessoas tendem a moldar seu comportamento de acordo com as suas atitudes.

Neiva (2004) defende as atitudes dos indivíduos como fundamentais na relação com a mudança organizacional, principalmente as atitudes frente à mudança. Continua que a implementação de mudanças implica em reações, as vezes não intencionais como: recusa, resistência, estresse, cinismo ou redução do comprometimento. Para Damanpour (1991 apud NEIVA, 2004) as atitudes dos gerentes são essenciais para o sucesso na implantação de mudanças. Neiva (2004) converge no entendimento em relação aos elementos de cognição, afetação e comportamento já citado. Aponta ainda que o estudo das reações pode servir de base para a análise da capacidade de mudança de comportamento dos indivíduos que se mostra necessário para o sucesso na implementação de mudanças, ou seja, para que se tenha sucesso em uma mudança é necessário que os indivíduos envolvidos mudem seu 
comportamento. Defende que as atitudes de aceitação frente às mudanças levam a comportamentos favoráveis o que aumenta as possibilidades de adaptação e sucesso. Já as atitudes de negação, entre elas o temor, diminuem a probabilidade de sucesso na nova forma adotada. Para a autora sem mudança no comportamento individual não haveria mudança organizacional em larga escala.

Para Piderit (2000 apud NEIVA, 2004) é possível a ocorrência de ambiguidades, o que significaria a possibilidade de um mesmo indivíduo apresentar médias na avaliação de atitude contrastantes bem próximas, o que seria um mesmo indivíduo apresentar médias altas de atitudes de temor e aceitação ao mesmo tempo. Isso remeteria a necessidade de avaliar as respostas dos indivíduos dentro conceito de Psicologia Social, já descrita, baseada em comportamentos passados ou intenções futuras.

Robbins (2005, p. 63) traz ainda a teoria da dissonância cognitiva proposta por Leon Festinger, que se estabelece como: “A dissonância cognitiva se refere a qualquer incompatibilidade que um indivíduo percebe entre duas ou mais de suas atitudes ou entre sua atitude e seu comportamento”. Esta teoria explicita a dificuldade do indivíduo em se comportar de acordo com as suas atitudes por conta de fatores internos ou externos à organização que influenciem no processo. Para o autor, segundo Festinger, as pessoas buscam um mínimo possível de dissonância, mesmo que para isso o indivíduo promova mudança na sua atitude de forma a amenizar a inconsistência, ou quando insuperável abandonam a organização. Outros aspectos importantes seriam os moderadores da dissonância entre eles a importância, a escolha e a recompensa.

As atitudes que espelham valores fundamentais, ou que convergem com os interesses da pessoa ou grupos são caracterizadas como importantes e podem correlacionar mais fortemente com o comportamento. Se as pessoas consideram determinada dissonância como sendo algo sobre o qual não se tem escolha mostram-se menos propensos a mudar de atitude. Por outro lado se a recompensa é significativa para o indivíduo ele tende a reduzir a dissonância mudando, ou adaptando a sua atitude de forma a minimizar a inconsistência. Conclui o autor, que se os indivíduos não consideram importantes os fatos que causam a dissonância, ou se tais fatos são de imposição externa, ou incontroláveis, ou que as recompensas não sejam consideradas significativas, não se obterá pressão suficiente para induzir uma mudança de atitude. 


\section{3 - METODOLOGIA}

Woodman (1998 apud NEIVA, 2003) propõe um paradigma de avaliação da mudança que consiste no uso de abordagens metodológicas qualitativas e quantitativas que levem a observação das dimensões da qualidade e/ou importância da intervenção, relações entre o efeito do interventor e da intervenção.

Para esta pesquisa foram adotadas duas formas de abordagem, uma parte quantitativa complementada por uma análise documental, qualitativa.

\section{1 - Tipo de pesquisa}

Para esta pesquisa foi adotada uma abordagem quantitativa complementada por pesquisa documental.

A análise quantitativa visou a obtenção de dados para a caracterização das atitudes dos servidores frente a processos de mudança ocorridos na organização, bem como a caracterização desses grupos. Foi realizada a partir de um levantamento de dados (Survey). Freitas et al. (2000) caracterizam a pesquisa survey como: a obtenção de dados ou informações sobre características, ações ou opiniões de grupos específicos, representantes de uma população alvo, cujo interesse seja produzir descrições quantitativas. Pinsonneault e Kraemer (1993 apud FREITAS et al., 2000) classificam a pesquiva survey quanto ao seu propósito, entre elas a descritiva, a qual busca identificar quais opiniões, eventos ou atitudes estão manifestas em uma população, descreve a distribuição de fenômenos em uma população ou subgrupos, permitindo comparações. Para esta pesquisa foi adotado um procedimento denominado corte-transversal (cross-sectional) definido por Freitas et al. (2000) como uma classificação quanto ao momento da coleta dos dados, que nesse caso significa que a coleta de dados, descrição e análise das variáveis ocorreram em um só momento.

Na pesquisa documental foi adotada a análise de documentos para a caracterização da organização pesquisada, bem como subsidiar a seleção da amostra.

\section{2 - Caracterização da organização}

A organização pesquisada tem sua sede na Capital Federal e jurisdição em todo o território nacional e tem como atribuição: a uniformização da jurisprudência 
infraconstitucional. A organização funciona em Plenário (todos os julgadores) e pelo seu órgão especial denominado Corte Especial (15 julgadores).

A organização pesquisada apresenta um universo de 2.604 servidores ativos, lotados em 114 unidades de acordo com a estruturação encontrada no dia 10/07/2008. O quantitativo de servidores divididos em áreas Meio e Fim. A Área Meio é responsável pela parte administrativa da instituição, entre elas, a gestão de pessoas, administração das instalações, segurança, documentação, saúde entre outros do gênero. A Área Fim esta voltada para a atividade judicante sendo responsável por todas as etapas dos processos judiciais dentro da organização. Uma variante da Área Fim seria os gabinetes, que são estruturas disponíveis aos julgadores e que dispõe de certa autonomia dentro da organização. Ressalta-se a participação de um número expressivo de terceirizados e de estagiários os quais complementam o trabalho dos servidores ativos.

\section{3 - População e amostra}

De acordo com Freitas et al. (2000) não há amostra perfeita, o que ocorre seria uma variação no grau de erro ou viés. Apontam como essencial a definição dos objetivos e critérios de elegibilidade dos respondentes, como forma de garantir a adequação da amostra. Esses autores acrescentam que o tamanho da amostra depende do número de respondentes necessários para a obtenção de resultados confiáveis, e que até certo limite o aumento do tamanho da amostra diminui o erro.

Conforme já descrito a instituição pesquisada possui uma população de 2.604 servidores ativos, lotados em 114 unidades. Para esta pesquisa, foi adotado um agrupamento em três segmentos os quais considerou as especificidades das funções dentro da organização assim representadas: Área meio com 1.253 servidores; Área fim com 668 e Gabinetes com 664.

No presente estudo, a amostra não foi obtida dentro dos critérios probabilísticos, tendo sido selecionada com base na representatividade de cada área e composta por cerca de 12,44\% da população total dos servidores divididos entre as três áreas descritas. Assim, o número de servidores pesquisados na área meio foi de 109 servidores, na área fim 113 servidores e nos gabinetes 102 servidores.

Em relação aos documentos, a amostra foi composta por Atos oficiais, portarias, instruções normativas e regimento interno da instituição. 


\section{4 - Instrumento}

Neiva (2004) construiu e validou uma escala de atitudes frente à mudança elaborada com base em entrevistas com profissionais de recursos humanos. A partir da análises das entrevistas e da literatura foi hipotetizada estrutura bi-fatorial englobando atitudes de aceitação e negação dos indivíduos frente ao processo de mudança. Os itens foram submetidos a análise fatorial que evidenciou a presença de três fatores: ceticismo, temor e aceitação. Para autora, tais fatores representam as atitudes características dos indivíduos submetidos a um processo de mudança. O ceticismo engloba atitudes ou os comportamentos negativos em relação ao processo de mudança. O temor reflete o medo da perda de poder, benefícios além das incertezas vividas pelos membros da organização. Por fim, a aceitação contempla os comportamentos positivos em relação ao processo de mudança.

Neste estudo foi realizado um sorteio para a disposição dos itens do instrumento. Pretendeu-se avaliar a atitude dos servidores em diversos agrupamentos, de forma que possibilitassem a obter uma visão geral da atitude da organização. Uma única alteração em relação ao instrumento diz respeito a numeração da escala onde se apresenta como número um 1- discordo totalmente; 2 - discordo pouco; 3 - não discordo nem concordo; 4 - concordo pouco; 5 - concordo totalmente, ao invés do zero (0) da escala original.

Para Godoy (1995a), a análise de documentos apresenta-se como uma valiosa técnica de abordagem de dados qualitativos, podendo ser utilizada como complemento para dados obtidos de outras fontes. Corroboram nesse entendimento, Lüdke e André (1987) acrescentando a possibilidade da revelação de novos aspectos acerca de um tema ou problema. Para esses autores a caracterização dos documentos a serem analisados não é aleatória, pois haveria sempre uma idéia, hipótese ou propósito orientando a escolha. No presente estudo a análise documental objetivou caracterizar como a instituição pesquisada era organizada, qual a sua cadeia de valor, para a orientação da representatividade das áreas a serem pesquisadas, além de propiciar a análise dos atos administrativos referentes a reestruturações ocorridas em épocas de mudança na presidência da instituição.

\section{5 - Procedimentos de coleta de dados}

Os questionários foram distribuídos durante o mês de novembro diretamente nas unidades selecionadas previamente, em envelopes que permitiam serem lacrados, além de estarem endereçados ao pesquisador, após uma semana, em média, eram recolhidos. 
Os documentos, referente à análise documental, foram acessados no banco de dados, referentes às comunicações oficiais, disponíveis para consulta na intranet da organização, ou então solicitados junto às unidades responsáveis.

\subsection{Análise das informações}

Em relação ao instrumento, de acordo com Freitas et al. (2000) um survey deve ser analisado por meio de ferramental estatístico apropriado que permita a obtenção das informações desejadas. Para as variáveis nominais, os autores apresentam a contagem do número de casos, uma vez definido o atributo estudado, estabelecem-se comparações entre as categorias utilizando-se de proporções, porcentagens e razões. Para as variáveis intervalares os autores apontam a possibilidade de comparação entre as diferenças numéricas entre categorias, e as possibilidades estatísticas entre elas: média aritmética, desvio-padrão, correlação de postos, correlação produto-fenômeno.

De acordo com Freitas e Moscarola (2002), após a aplicação do instrumento deve-se realizar o tratamento dos dados os quais podem ocorrer de três formas: a análise univariada, que descreve uma variável por vez; a análise bi-variada ou tabulação cruzada onde se busca identificar a relação entre a resposta e a pergunta; a análise multivariada, considerado método sofisticado, que analisam simultaneamente diversas variáveis. Apresenta-se, então, o aparato para a análise dos dados a serem coletados pelo instrumento nesta pesquisa.

Neste estudo foram calculadas as médias e desvios padrão dos fatores representativos das atitudes dos servidores (ceticismo, temor e aceitação) nos agrupamentos das áreas de atuação do respondente. Além disso, foram realizadas correlações entre as variáveis demográficas tais como: idade, escolaridade, tempo de serviço na organização, função comissionada atualmente ocupada e os fatores, a fim de verificar possíveis relações entre as atitudes e as referidas variáveis. Como complemento foram ainda realizadas a regressão linear e análise de variância para verificação da homogeneidade dos dados dentro dos grupos que apresentaram correlação significativa. Na análise estatística dos dados foi utilizado o software Statiscal Package for Social Sciences (SPSS) for Windows versão 15.0. 


\section{RESULTADOS}

Os resultados obtidos após a etapa de a aplicação do instrumento de avaliação junto aos servidores da instituição são apresentados da seguinte forma: primeiramente, a caracterização do perfil dos respondentes com relação aos dados demográficos. Em seguida as médias e os desvios padrão do grupo geral e dos subgrupos, de acordo com as áreas de atuação (Área Meio, Área Fim e Gabinete) cujas correlações se mostraram significativas. Para melhor compreensão, essas correlações foram agrupadas em quadros separados pelos fatores pesquisados, a fim de possibilitar um maior aprofundamento na análise.

Tabela 1. Composição da amostra

\begin{tabular}{lccc}
\hline & Grupo & $f$ & $\%$ \\
\hline Área Meio & 109 & 33,6 \\
\hline Área Fim & 113 & 34,9 \\
\hline Gabinete & 102 & 31,5 \\
\hline Total & 324 & 100 \\
\hline
\end{tabular}

A amostra foi desmembrada de forma a identificar subgrupos aqui denominados de Área Meio, Área Fim e Gabinete de forma que possibilitassem a investigação das atitudes dos servidores da instituição além de algum aspecto relevante nesses subgrupos. Destaca-se que a amostra representa aproximadamente $12,44 \%$ da população de servidores da instituição à época da obtenção dos dados.

Tabela 2. Médias e Desvios-padrão dos fatores de atitude frente à mudança do grupo geral e subgrupos

\begin{tabular}{cccc}
\hline Área & Fator & Média & Desvio-Padrão \\
\hline Geral & Temor & 4,03 & 0,55 \\
& Aceitação & 3,69 & 0,61 \\
& Ceticismo & 3,20 & 0,67 \\
\hline Área Meio & Temor & 4,12 & 0,52 \\
& Aceitação & 3,69 & 0,62 \\
& Ceticismo & 3,37 & 0,67 \\
\hline Área Fim & Temor & 4,05 & 0,51 \\
& Aceitação & 3,52 & 0,61 \\
& Ceticismo & 3,22 & 0,59 \\
\hline Gabinetes & Temor & 3,90 & 0,62 \\
& Aceitação & 3,88 & 0,53 \\
& Ceticismo & 3,00 & 0,71 \\
\hline
\end{tabular}

A partir do quadro das médias e desvio-padrão pode-se verificar que o fator temor obteve as maiores médias em todos os grupos apresentados. No grupo geral, o fator temor obteve média de 4,03, enquanto que o grupo da Área Meio apresentou a maior média com 
valor de 4,12, e o grupo Gabinete a menor 3,90. O fator aceitação apresenta-se como o segundo fator a receber as maiores médias onde a geral foi de 3,69, enquanto que a maior apresentada foi a do grupo Gabinete 3,88 e a menor foi a do grupo Área Fim 3,52. O fator ceticismo foi o que recebeu as menores médias em relação aos demais e o grupo geral obteve média de 3,20 e a maior média foi do grupo Área Meio 3,37 e a menor média o grupo Gabinete 3,00. Em relação as médias apresentadas significa dizer que os grupos que apresentaram médias entre 4,0 e 5,0 (4 - concordo pouco; 5 - concordo totalmente). Já os grupos que se apresentaram as médias entre 3,0 e 4,0 apresentaram resposta entre não concordam e nem discordam até concordam pouco.

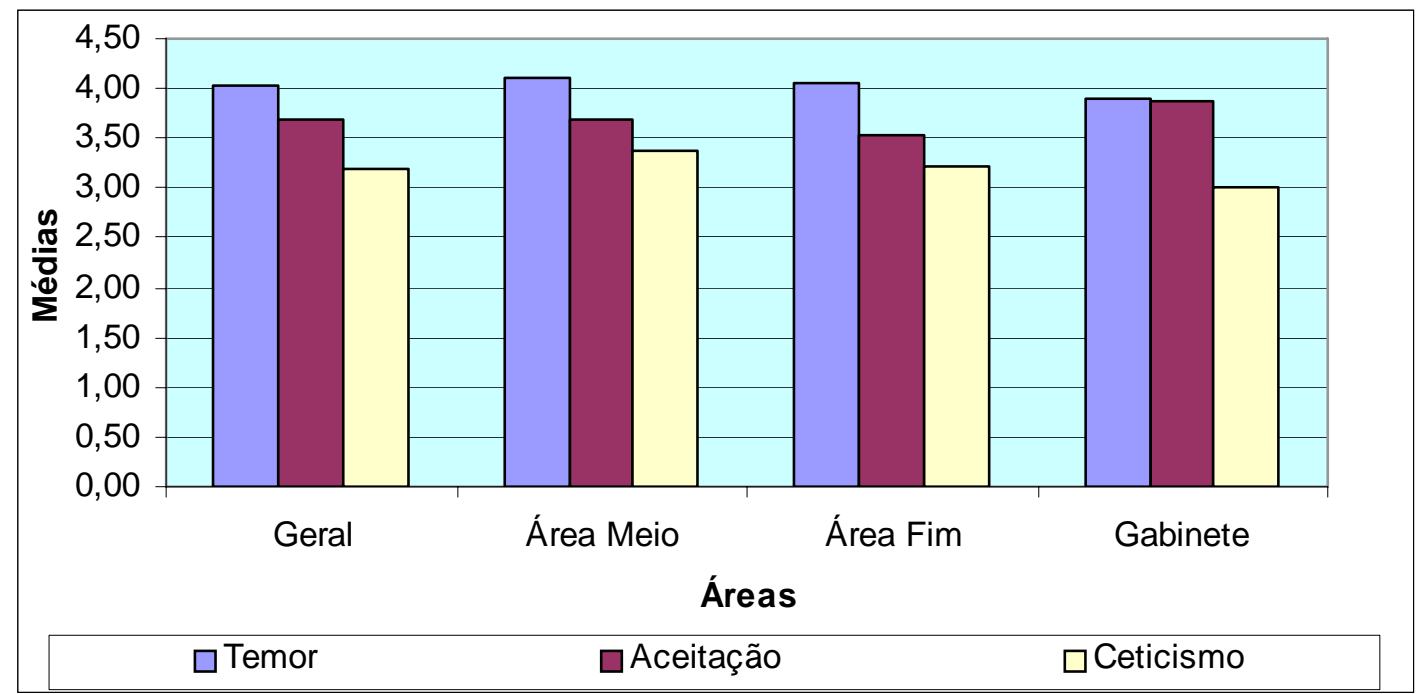

Gráfico 1. Médias das atitudes do grupo geral e subgrupos.

Para melhor compreensão e visualização da percepção dos participantes da pesquisa foram apresentados no gráfico 1 as médias e os desvios-padrão dos fatores para o grupo geral e seus três principais subgrupos. Esse gráfico permite a observação do comportamento das respostas de cada grupo, além de destacar o comportamento, em relação às atitudes do grupo gabinete que se apresenta com alguma variação, já relatada, ao apresentar as médias, com relação ao temor e à aceitação, bastante próximas.

Com o objetivo de avaliar a percepção dos servidores quanto ao processo de substituição na presidência da instituição seria reconhecida como motivador de mudança nas unidades, foram elaboradas duas questões com a utilização da mesma escala do instrumento de avaliação das atitudes (1- discordo totalmente; 2 - discordo pouco; 3 - não discordo nem concordo; 4 - concordo pouco; 5 - concordo totalmente) onde os resultados são apresentados a seguir. 
Tabela 3 Médias e Desvios Padrão da percepção da influência da presidência da organização nos processos de mudança.

\begin{tabular}{ccc}
\hline Áreas & $\begin{array}{c}\text { Você concorda que a mudança na } \\
\text { presidência da instituição afeta de } \\
\text { alguma forma o desempenho da } \\
\text { sua unidade? }\end{array}$ & $\begin{array}{c}\text { Você associa os principais } \\
\text { processos de mudança na sua } \\
\text { unidade à mudança na presidência } \\
\text { da instituição? }\end{array}$ \\
\hline Meio & $\mathrm{M}=4,17$ & $\mathrm{M}=3,88$ \\
& $\mathrm{DP}=1,15$ & $\mathrm{DP}=1,27$ \\
\hline Fim & $\mathrm{M}=3,85$ & $\mathrm{M}=3,58$ \\
& $\mathrm{DP}=1,26$ & $\mathrm{DP}=1,28$ \\
\hline Gabinete & $\mathrm{M}=3,38$ & $\mathrm{M}=2,69$ \\
& $\mathrm{DP}=1,27$ & $\mathrm{DP}=1,25$ \\
\hline
\end{tabular}

Ao serem questionados sobre a sua unidade teria o seu desempenho afetado de alguma forma pelo processo de mudança na direção da organização, os servidores da área meio apresentaram a maior média 4,17 (4 - concordo pouco; 5 - concordo totalmente). Já o segundo quesito que questionava se o respondente associava os principais processos de mudança ocorridos na sua unidade ao processo de mudança na presidência, a média para a mesma área meio foi de 3,88. O grupo que apresentou as menores médias para os quesitos já descritos foi o grupo gabinete: média 3,38 para o primeiro e média 2,69 para o segundo. Deve-se destacar a impropriedade na elaboração dos itens para o fato de se apresentarem forçando uma determinada resposta, o que não é recomendado, mas que não inviabiliza uma observação dos resultados.

Foram calculadas correlações entre as variáveis demográficas e os fatores de atitudes frente à mudança para identificação de atitudes que pudessem ser explicadas por alguma variável. As correlações significativas encontram-se na tabela a seguir.

Tabela 4. Correlações de Pearson significativas para o fator Ceticismo.

\begin{tabular}{lcccc}
\hline Grupo & Idade & $\begin{array}{c}\text { Tempo de } \\
\text { serviço }\end{array}$ & Escolaridade & FC ocupada atualmente \\
\hline Geral & $\begin{array}{r}\mathrm{r}=-0,132^{*} \\
\mathrm{p}=0,020\end{array}$ & $\mathrm{r}=-0,198^{*}$ & $\mathrm{r}=0,195^{*}$ & $\mathrm{r}=0,159^{* *}$ \\
$\mathrm{p}=0,006$
\end{tabular}

* Correlation is significant at the 0.05 level (2-tailed)

** Correlation is significant at the 0.01 level (2-tailed) 
A observação das correlações relacionadas ao fator ceticismo mostrou que para o grupo geral dos respondentes quanto maior a faixa etária menor a tendência para o ceticismo. Já em relação às funções comissionadas (FC) ocupadas à época da pesquisa, a relação se apresenta de forma inversa, pois a tendência é que quanto maior a FC ocupada atualmente maior a tendência para o ceticismo. A Área Meio apresentou a correlação significativa para a variável escolaridade onde a tendência ao ceticismo aumentaria quanto maior o grau de escolaridade. A Área fim apresentou resultados no mesmo sentido que o grupo geral para as mesmas variáveis (idade e FC ocupada atualmente) com destaque para o percentual explicado ser maior para essa área em comparação com o grupo geral.

Todos os grupos analisados não apresentaram distribuição linear dos dados, ou seja, não se comportaram como uma curva normal, o que força o entendimento de que mesmo que haja correlações significativas não é possível, com bases estatísticas, assegurar que os grupos irão se comportar da forma predita pelas correlações. Isso restringe a confiabilidade das análises apresentadas como um estudo pontual, ou seja, não é possível a extrapolação das análises para além do momento da pesquisa.

Com o objetivo de tentar a determinação de um modelo que pudesse explicar o comportamento das atitudes em função de alguma variável demográfica foi realizada a regressão linear entre os grupos que apresentaram correlações significativas entre os fatores pesquisados e as variáveis demográficas correspondentes, conforme tabela 4. Para exemplificação serão apresentados a seguir os resultados obtidos da regressão linear entre o grupo geral para o fator ceticismo e a variável idade do servidor.

Tabela 5. Coeficientes de correlação e de determinação da relação do grupo geral para o fator ceticismo e a variável idade do servidor.

Model Summary

\begin{tabular}{cccc}
\hline $\mathrm{R}$ & $\mathrm{R}$ Square & $\begin{array}{c}\text { Adjusted R } \\
\text { Square }\end{array}$ & $\begin{array}{c}\text { Std. Error of } \\
\text { the Estimate }\end{array}$ \\
\hline, 132 &, 018 &, 014 &, 661 \\
\hline \multicolumn{2}{l}{ The independent variable is idade. }
\end{tabular}

The independent variable is idade.

O cálculo regressão linear para o grupo geral em relação ao fator ceticismo e a idade dos servidores como tentativa de um modelo explicativo evidenciou a ocorrência da dispersão dos dados, pois ainda que se tenha obtido uma correlação significativa o $\mathrm{R}^{2}$ é muito baixo $(0,018)$ o que impede a explicação do evento através da regressão. 
Tabela 6. Análise de variância da relação do grupo geral para o fator ceticismo e a variável idade do servidor.

ANOVA

\begin{tabular}{cccccc}
\hline & Sum of & & & & \\
& Squares & df & Mean Square & $F$ & Sig. \\
\hline Regression & 2,396 & 1 & 2,396 & 5,481 &, 020 \\
Residual & 134,197 & 307 &, 437 & & \\
Total & 136,593 & 308 & & & \\
\hline
\end{tabular}

The independent variable is idade.

A análise da variância (ANOVA) para o grupo geral e tendo como variável dependente o fator ceticismo e como variável independente idade do servidor revelou um valor considerado baixo para a relação entre a variância explicada e a não explicada $(F=5,481)$, 0 que reafirma a tendência de dispersão dos dados.

Tabela 7. Correlações de Pearson significativas para o fator Temor

\begin{tabular}{cc}
\hline Grupo & Tempo de serviço (instituição) \\
\hline Gabinete & Pearson Correlation $=-0,258^{*}$ \\
& Sig. (2-tailed) $=0,012$ \\
\hline
\end{tabular}

*Correlation is significant at the 0.05 level (2-tailed)

Para o fator Temor, o grupo gabinete apresentou correlação significativa para a variável tempo de serviço. O sinal da correlação indica que para os respondentes desse grupo quanto maior o tempo de serviço na organização menor seria a tendência às atitudes de temor. Essa correlação explicita que cerca de $26 \%$ do temor apresentado pelo grupo, no momento da avaliação, diminuiria em conseqüência do aumento do tempo de serviço na instituição para um erro de estimativa de $5 \%$.

A seguir, esses resultados serão discutidos à luz da literatura revisada. 


\section{DISCUSSÃO}

Para Neiva (2004) as atitudes dos indivíduos são fundamentais na relação com a mudança organizacional. Defende que as atitudes de aceitação frente às mudanças levam a comportamentos favoráveis o que aumenta as possibilidades de adaptação e sucesso. Já as atitudes de negação, entre elas o temor, diminuem a probabilidade de sucesso na nova forma adotada. Para a autora, sem mudança no comportamento individual não haveria mudança organizacional em larga escala.

É importante destacar que atitudes negativas frente à mudança não devem ser confundidas com resistência, as quais deverão ser utilizadas apenas como indicativos de potencial comportamento. As atitudes, como parte da subjetividade do indivíduo ou de grupos, poderão influenciar ou não em um possível comportamento. Existem muitos fatores que poderão interferir na expressão do comportamento real. Robbins (2005) destaca que as atitudes são menos estáveis do que os valores desenvolvidos pelos indivíduos. Isso revela a possibilidade de serem mudadas, ou seja, são passíveis de sofrerem interferências a partir de influenciadores, ou motivadores, por outro lado revela também a possível dificuldade de serem mantidas.

Os resultados indicaram que as maiores médias foram para os fatores temor e aceitação, dando a sensação de ambigüidade em relação às atitudes. Segundo Neiva (2004) alguns autores destacavam que a presença de atitudes opostas, ou seja, atitudes de temor e aceitação frente à mudança, fenômeno denominado de ambigüidade, como uma premissa que antecede os comportamentos de resistência às mudanças. Essa ambigüidade, segundo os autores, não favorece a mudança de comportamento, embora não estejam definidas formas de medir a ambigüidade. Sugerem que as médias altas e próximas uma da outra, de atitudes positivas e negativas à mudança, possam ser uma possibilidade de medida.

Neiva (2004) em suas considerações, sobre o estudo realizado por ela, apontou que a atitude de temor muito presente naquela organização poderia funcionar como indicador de avaliação negativa indicando que a referida organização teria potencial para ser uma organização cínica e com tendência a resistência. Embora este trabalho tenha apresentado resultado demonstrando uma predominância das atitudes de temor, as análises estatísticas não evidenciaram a homogeneidade deste fator o que não se pode assegurar um comportamento semelhante ao relatado no estudo da referida autora.

Uma inferência nos dados coletados revelou a predominância de não linearidade na sua distribuição, o que não permitiu apontar a probabilidade dos eventos se repetirem no 
futuro, ou seja, indica que este estudo sobre as atitudes apenas deve ser considerado dentro de uma avaliação pontual.

Uma possibilidade de explicação para a não linearidade dos dados seria a estabilidade das atitudes dentro do processo cognitivo individual, ou seja, conforme já citado por Robbins (2005) que apresenta as atitudes como menos estáveis que os valores. Dessa forma, as pessoas poderiam mudar de atitude dependendo da situação a que fossem submetidos. Com base nessas considerações, seria coerente a não linearidade apresentada, pois, quando exposto a situações hipotéticas no instrumento (variáveis) não se esperaria do respondente uma opinião mais profunda sobre todas, talvez somente aquelas quais tenham tido vivenciado seria possível a expressão mais segura da atitude.

Outra possibilidade de explicação para a não linearidade estaria na diversidade da população pesquisada seja pela idade, escolaridade, tempo de serviço na organização, entre outros, até mesmo o momento pessoal do servidor pode contribuir significativamente para o resultado apresentado.

Para o fator temor, é possível, com base nas características da organização, tentar compor cenários para as principais possibilidades ante o resultado apresentado. Segundo Neiva (2004) a escala elaborada para a avaliação das atitudes, no que se refere ao temor, refletiria o medo da perda de poder, benefícios e incertezas vividas em momentos de mudança. Com base nessas premissas e no que foi possível ser avaliado na organização pesquisada, as atitudes de temor apresentadas poderiam ser expressas por cenários tais como: temor que o processo de mudança leve o servidor a perder a função comissionada, ou que ocorra aumento no volume de trabalho, ou então que haja aumento de complexidade para a execução da nova tarefa, ou que venha a mudar o turno de trabalho, que o leve a mudar de unidade ou a se separar de colegas.

Em outra abordagem, o receio apresentado pela organização poderia estar ligado a um certo grau de satisfação com a organização, com a unidade, ou com os processos de trabalho. Nesse contexto, é coerente assinalar que o temor pode ser expresso em diversos níveis, onde se presume que as atitudes temerosas seriam maiores quando ameaçadas as recompensas e/ou as regalias, do que quando ameaçado somente o conforto, ou o aumento no esforço para desempenho das tarefas. Seria razoável considerar que, dentro do contexto da pesquisa, um mesmo respondente apresentasse concordância em níveis diferentes ou não para situações diferentes, por exemplo, um servidor pode temer uma mudança em que possa perder uma função comissionada, ao mesmo tempo em que possa apresentar aceitação para mudanças que alterem processos de trabalho. 
O fator aceitação é disposto por Neiva (2004) como sendo uma avaliação sobre as crenças e comportamentos positivos frente a processos de mudança. As atitudes de aceitação frente à mudanças apresentadas pela organização poderiam ser explicadas, em parte, por uma insatisfação com a organização, unidade, ou processos de trabalho, bem como refletir o desejo individual, ou de grupos para ascensão a posições gerenciais, ou seja, ocupar um espaço na organização. Também poderia ser uma atitude de quem deseja mudar processos de trabalho como resposta às necessidades da organização, e como forma de manter uma posição. Numa outra perspectiva poderia haver uma ligação com uma suposta inconsistência entre os valores da organização e os do servidor.

Para o fator ceticismo, Neiva (2004) destaca que essas atitudes enfatizariam o descrédito e a não-colaboração dos servidores em processos de mudança. Dentro do contexto da organização pesquisada poderia, em parte, serem associadas atitudes de ceticismo a algum tipo de frustração vivido pelo servidor. As atitudes apresentadas poderiam ser explicadas pelos cenários: Servidores que estão na organização momentaneamente, ou seja, não planejam permanecer na instituição, por servidores que, assumindo postos gerenciais, tiveram frustrada a execução de mudanças seja por falta de autonomia, ou por falta de apoio. As incertezas quanto a evolução da carreira, juntamente com a frustração que pode ser apresentada por novos servidores com alto nível de escolaridade e capacitação que não vislumbraram possibilidades de evolução, ou se apresentam frustrados em realizarem trabalhos burocráticos catalisado pela elevada expectativa quando do ingresso na instituição. As atitudes de ceticismo também poderiam ser expressas por servidores que tiveram experiências negativas em relação a algum processo de mudança executado anteriormente. As atitudes de ceticismo poderiam estar ligadas a situações nas quais o servidor demonstra pouco envolvimento com a organização, seus valores e objetivos.

Ao se analisar a relação do temor com uma possível satisfação do servidor com a organização, ou com a manutenção de um status quo, e com base na ambigüidade como precursora de resistências, pode-se inferir que a organização apresenta indícios de um potencial para desenvolver comportamentos resistentes. Porém, ao se observar as características deve ser considerada uma outra possibilidade, uma vez que na organização pesquisada as mudanças mais significativas, principalmente as que envolvem reestruturações e que normalmente afetam funções comissionadas, serem introduzidas top down a despeito da participação ou aquiescência dos servidores. Não se verificou na organização uma postura frontalmente de oposição a qualquer processo significativo de mudança, pois parece não haver coesão suficiente nos grupos para desencadear um processo de resistência que pudesse ser 
considerado expressivo. O elevado número de funções comissionadas oferece a administração da organização um elevado poder de amenizar possíveis resistências. A observação que dos 324 (trezentos e vinte e quatro) respondentes da pesquisa 211 (duzentos e onze) ocupam uma função comissionada no momento, expressa as possibilidades de um servidor vir a ocupar uma função em algum momento sejam consideráveis. Esse quadro fortalece um possível entendimento de reflexos nas atitudes e no comprometimento do servidor com a organização.

Uma abordagem realizada neste estudo é quanto à percepção dos servidores em relação ao processo de substituição na presidência da organização e as mudanças nas suas unidades. A análise dos resultados sugere a existência de uma percepção diferenciada entre as áreas pesquisadas. A área meio apresentou as maiores médias enquanto o grupo gabinete apresentou as menores. O resultado dessa superficial investigação sugere que as áreas mais expostas às ações administrativas da presidência desenvolveram uma percepção maior quanto ao evento. Uma análise dos atos administrativos demonstrou a ocorrência de várias reestruturações da área administrativa, e até mesmo na área fim, as quais ocorreram, geralmente, após a posse de um novo presidente.

O estudo atual não permite um maior aprofundamento neste aspecto. Porém, evidencia o impacto do evento na percepção dos servidores das áreas meio e fim. A importância da ação da presidência junto a essas áreas merece atenção na forma de avaliar os impactos junto aos servidores. Se a instituição de uma forma geral apresentou atitude de temor ao mesmo tempo em que duas áreas reconheceram a mudança na presidência como grande motivador das mudanças revela-se a responsabilidade com que devem ser conduzidas a ações de mudança, pois podem estar diretamente ligadas às atitudes atuais dos servidores.

A percepção, neste estudo, de que as atitudes apresentadas não dependem da área de atuação do servidor não invalida o raciocínio de que a área de atuação possa influenciar o desenvolvimento de determinadas atitudes. Neste contexto, as áreas de atuação passariam a ser importantes atores se propiciassem aos servidores uma configuração que favorecesse o desenvolvimento de atitudes positivas para as mudanças, ao invés de esperarem que estas ocorram espontaneamente. Um estudo que demonstrasse as características favoráveis e desfavoráveis ao desenvolvimento de atitudes positivas frente a mudanças, em cada área da organização, poderia ser um importante ponto de partida para o gerenciamento das atitudes na instituição. O estudo da cultura e a configuração de poder, entre outros, de cada área poderia ajudar a entender melhor qual ambiente o servidor estaria exposto, a que tipos de pressão são submetidos, e como cada área lida com a mudança. Poderiam ser aspectos importantes para o 
planejamento de um contexto favorável ao desenvolvimento de atitudes positivas para mudança.

O estudo isolado das atitudes, ao menos neste trabalho, não se mostrou suficiente para concluir que houvesse resistência à mudança, o que ocorreu foi a detecção de um potencial de resistência. As correlações apresentadas demonstraram características das atitudes, principalmente aquelas ligadas à função comissionada, por estarem relacionadas ao ceticismo e não ao temor, porém revela-se necessário que se desenvolva um entendimento que estas funções poderiam ser utilizadas dentro de uma configuração que pudesse favorecer as atitudes positivas e não as negativas conforme apresentado. 


\section{6. - CONCLUSÕES}

O presente estudo tinha como objetivo avaliar as atitudes dos servidores de uma instituição do judiciário, que se mostravam inexploradas até então. Destaca-se que o que foi analisado no presente estudo foi o posicionamento dos servidores frente a situações hipotéticas a eles submetidas e que os resultados obtidos devem ser observados sob a ótica de um potencial que pode, ou não, vir a ser expresso. Isso significa que não deve ser feita a relação direta entre atitudes negativas e resistência à mudança. Outro aspecto desta pesquisa é que a mesma não aborda as atitudes dos juízes, mas tão somente as atitudes dos servidores.

Uma possível descrição da instituição, com base na investigação realizada, seria a de uma organização com o predomínio de atitudes de temor às mudanças e em seguida das atitudes de aceitação, características de uma organização ambígua e com razoável nível de estabilidade, o que caracteriza um ambiente com potencial de resistência à mudança e em menor escala um potencial para o não comprometimento. Esse último ligado às atitudes de ceticismo.

O presente estudo possibilitou evidenciar a ocorrência de uma diversidade das atitudes na organização. Outro fator relevante a ser destacado é fato da distribuição dos dados não ter apresentado um comportamento dentro dos critérios da curva de normalidade, ou seja, não foram homogêneos o suficiente para que se pudessem extrapolar os resultados para além do momento pesquisado, possivelmente por uma relação direta com a instabilidade das atitudes. Apontou uma possibilidade das atitudes serem influenciadas no sentido desejado pela organização, porém a mesma instabilidade perante fatores externos e internos à organização pode apresentar alguma dificuldade em se manter, ou seja, pode ser difícil para a organização manter as atitudes desejadas.

Não ficou evidenciado que o fato do servidor pertencer a uma ou outra área de atuação tenha sido relevante para o estudo das atitudes, porém destacam-se as áreas como imprescindíveis para propiciar o ambiente favorável ao desenvolvimento das atitudes positivas frente às mudanças. Neste contexto surge a necessidade de estudos que possam demonstrar as características favoráveis e desfavoráveis ao desenvolvimento de atitudes positivas frente a mudanças, em cada área da organização, o qual poderia ser um importante ponto de partida para o gerenciamento das atitudes na instituição. O estudo da cultura e a configuração de poder, entre outros, de cada área poderá ajudar a entender melhor qual ambiente o servidor é exposto, e a que tipos de pressão são submetidos, além de como cada área lida com a mudança. Esses aspectos se mostram importantes para o planejamento de um 
contexto favorável ao desenvolvimento de atitudes positivas para mudança. Salientando a importância de um maior aprofundamento no entendimento da relação do comportamento com outras variáveis, pois um determinado comportamento organizacional não parece se expressar exclusivamente como produto das atitudes.

Um fator que deve ser ressaltado é que em estudos organizacionais o ideal seria que o pesquisador fosse uma pessoa fora da influência da organização, o fato do pesquisador pertencer a organização por um lado diminuir a imparcialidade, ou então alguma tipo de influência na forma de enxergar a organização, por outro, pode apresentar aspectos e detalhes que não seriam detectados por um pesquisador externo.

Conclui-se que o presente trabalho tenha alcançado o objetivo inicial de apresentar as primeiras impressões sobre as atitudes dos servidores de uma instituição do judiciário, certamente ainda não é suficiente para que sejam feitas afirmações conclusivas ficando ao campo das suposições, acredita-se que com a continuidade de estudos ampliando o espectro da investigação e com maior aprimoramento das técnicas, seja possível desvendar o universo do comportamento organizacional das instituições ligadas ao poder judiciário como forma de melhorar a sua gestão e conseqüentemente os serviços prestados à sociedade. 


\section{REFERÊNCIAS}

BRASIL. Constituição (1988). Emenda constitucional $n^{\circ}$ 45, de 31 de dezembro de 2004. Câmara dos deputados: coordenação de publicações. Brasília, 24. ed., p. 327 - 344, 2006.

BRUNO-FARIA, M. F. Criatividade, inovação e mudança organizacional. In: LIMA, M. V. (Org). Mudança Organizacional: teoria e gestão. Rio de Janeiro: Editora FGV, 2003. p. 111161.

COSTA, F. L.; CAVALCANTI, B. S. Mudança organizacional no setor público. Revista de Administração Pública. V. 5, n. 1, nov./ jan. 1991. p. 82-106.

FERNANDES, K. R.; ZANELLI, J. C. O processo de construção e reconstrução das identidades dos indivíduos nas organizações. Revista de Administração Contemporânea. v. 10, n. 1, jan/mar. 2006. p. 55-72.

FEUERSCHÜTTER, S. G. Cultura organizacional e dependência de poder: a mudança estrutural em uma organização do ramo de informática. Revista de Administração Contemporânea. v. 1, n.2, maio/ago. 1997. p. 73-95.

FREITAS, H. et al. O método de pesquisa survey. Revista de Administração, v. 35, n. 3, jul/set. 2000. p. 105 - 112.

FREITAS, H.; CUNHA JR, M. V. M.; MOSCAROLA, J. Aplicação de sistema de software para auxílio na análise de conteúdo. Revista de Administração, v. 32, n. 3, jul/set. 1997. p. 97-109.

FREITAS, H.; MOSCAROLA, J. Da observação à decisão: Métodos de pesquisa e de análise quantitativa e qualitativa de dados. Revista de Administração de Empresas-Eletrônica. v. 1, n. 1, jan/jun. 2002. p 1- 30.

GODOY, A. S. Introdução à pesquisa qualitativa e suas possibilidades. Revista de Administração de Empresas. São Paulo, v. 35, n. 2, mar/abr. 1995a. p 57-63.

A pesquisa qualitativa e sua utilização em administração de empresas. Revista de Administração de Empresas. São Paulo, v. 35, n. 4, mar/abr. 1995b. p 65-71.

GREY, C. O fetiche da mudança. Revista de Administração de Empresas-Eletrônica. v. 44, n. 1, jan/mar. 2004. p 10-25.

HERNANDEZ, J. M. C.; CALDAS, M. P. Resistência à mudança: uma revisão crítica. Revista de Administração de Empresas, São Paulo, v. 41, n. 2, abr/jun. 2001. p. 31-45. 
LEITÃO, S. P.; ROSSI, L. F. Natureza da mudança nas organizações: uma introdução crítica. Arché: interdisciplinar, Rio de Janeiro, v. 9, n. 28, 2000. p. 13-37.

LEITÃO, S. P; ROUSSEAU, K. Introdução à natureza da mudança na transformadora nas organizações na perspectiva da biologia cognitiva: Revista de Administração Pública. v. 5, n. 38, set/out. 2004, p. 683-710.

LIMA, M. V.; BRESSAN, C. L. Mudança organizacional: uma introdução. In: LIMA, M. V. (Org). Mudança Organizacional: teoria e gestão. Rio de Janeiro: Editora FGV, 2003. p. 1763.

LÜDKE, M.; ANDRÉ, M. L. Métodos de coleta de dados: observação, entrevista e analise documental. In: Pesquisa em educação: abordagens qualitativas. 6. reimp. São Paulo: EPU, 1986. cap. 3.

NEIVA, E. R. Metodologia para avaliação da mudança organizacional. In: LIMA, M. V. (Org). Mudança Organizacional: teoria e gestão. Rio de Janeiro: Editora FGV, 2003. p. 191215.

NEIVA, E. R. Percepção de mudança organizacional: o papel das atitudes e das características organizacionais. 2004. 239 f. Tese (Doutorado em Ciências-Psicologia) Universidade de Brasília, DF, Brasília. 2004.

NEIVA, E. R.; PAZ, M. G. T. Percepção de mudança organizacional: um estudo em uma organização pública brasileira. Revista de Administração Contemporânea, v.11, n. 1, jan/mar. 2007. p. 31-52.

RENAULT, S. R. T. A reforma do judiciário do poder judiciário sob a ótica do governo federal. Revista do Serviço Público. Brasília. v. 2, n.56, abr/jun 2005. p. 127-136.

ROBBINS, S. P. Valores, atitudes e satisfação com o trabalho. In: Comportamento organizacional. Trad. Reynaldo Marcondes. 11. ed. São Paulo: Pearson Prentice Hall, 2005. cap. 3.

ROBBINS, S. P. Mudança organizacional e administração do estresse. In: Comportamento organizacional. Trad. Reynaldo Marcondes. 11. ed. São Paulo: Pearson Prentice Hall, 2005. cap. 18.

SILVA, J. R. G; VERGARA, S. C. Sentimentos, subjetividade e supostas resistências à mudança organizacional. Revista de Administração de Empresas, São Paulo, v. 43, n. 3, abr/jun. 2003. p. 10 - 21.

SEABRA, S. N. A nova administração pública e mudanças organizacionais. Revista de Administração Pública, v. 4, n. 35, jul/ago 2001. p. 19 - 38. 
SIQUEIRA, M. M. M. Medidas do comportamento organizacional. Estudos de Psicologia (Natal), v. 7, n. spe, 2002. p. 11 - 18 


\section{ANEXOS}

ANEXO - A: Instrumento de pesquisa.

Você esta participando de uma pesquisa conduzida pela Universidade de Brasília (UnB) em parceria com a sua organização cuja a finalidade será estudar o que você pensa a respeito dos processos de mudanças organizacionais implementados em sua organização.

Sinta-se à vontade para responder à pesquisa lembrando-se que em nenhum momento você será identificado, nem a sua unidade de trabalho. As suas respostas ajudarão a entender um evento importante para a organização.

Não existe resposta certa ou errada, o importante é uma resposta consciente e sincera. 
Abaixo estão listados vários tipos de atitudes ou idéias que as pessoas podem ter sobre o processo de mudança organizacional. Pensando em sua organização, leia com atenção cada frase e informe o grau de concordância em cada uma delas.

- Não é necessária sua identificação, sendo garantido o sigilo das respostas, as quais serão analisadas em grupos dentro do contexto do tema;

- Não há resposta certa ou errada, circule ou sinalize o número da escala à direita do item que melhor representa seu entendimento conforme os códigos:

\begin{tabular}{|c|c|c|c|c|}
\hline $\begin{array}{c}1 \\
\text { DISCORDO } \\
\text { TOTALMENTE }\end{array}$ & $\begin{array}{c}2 \\
\text { DISCORDO } \\
\text { POUCO }\end{array}$ & $\begin{array}{c}3 \\
\text { NÃO DISCORDO } \\
\text { NEM } \\
\text { CONCORDO }\end{array}$ & $\begin{array}{c}\text { CONCORDO } \\
\text { POUCO }\end{array}$ & $\begin{array}{c}\text { CONCORDO } \\
\text { TOTALMENTE }\end{array}$ \\
\hline
\end{tabular}

\begin{tabular}{|c|c|c|c|c|c|}
\hline $\begin{array}{l}1 \text { - Em processos de mudança, costuma-se restringir o acesso a informações } \\
\text { para que oposição às mudanças não ocorra. }\end{array}$ & 1 & 2 & 3 & 4 & 5 \\
\hline 2 - As pessoas desenvolvem mecanismos para não mudar. & 1 & 2 & 3 & 4 & 5 \\
\hline $\begin{array}{l}3 \text { - As pessoas que estão à muito tempo no poder se sentem ameaçadas com a } \\
\text { mudança. }\end{array}$ & 1 & 2 & 3 & 4 & 5 \\
\hline 4 - As pessoas costumam negar que a mudança vai acontecer. & 1 & 2 & 3 & 4 & 5 \\
\hline $\begin{array}{l}5 \text { - Deixar que o tempo se encarregue da adaptação das pessoas ao novo é } \\
\text { uma prática comum nesta organização. }\end{array}$ & 1 & 2 & 3 & 4 & 5 \\
\hline 6 - Nos processos de mudança, as pessoas sentem medo de perder o emprego. & 1 & 2 & 3 & 4 & 5 \\
\hline $\begin{array}{l}7 \text { - As pessoas reagem negativamente às mudanças que geram perdas } \\
\text { salariais. }\end{array}$ & 1 & 2 & 3 & 4 & 5 \\
\hline $\begin{array}{l}8 \text { - Os servidores percebem que a maioria dos seus colegas de trabalho apóia } \\
\text { as mudanças na organização. }\end{array}$ & 1 & 2 & 3 & 4 & 5 \\
\hline 9 - Nos processos de mudança, o medo da perda gera resistência nas pessoas. & 1 & 2 & 3 & 4 & 5 \\
\hline $\begin{array}{l}10 \text { - As pessoas aceitam a mudança quando percebem que podem ganhar com } \\
\text { ela. }\end{array}$ & 1 & 2 & 3 & 4 & 5 \\
\hline $\begin{array}{l}11 \text { - A descentralização de poder gera temor porque há sentimento de perda } \\
\text { de controle e competência. }\end{array}$ & 1 & 2 & 3 & 4 & 5 \\
\hline $\begin{array}{l}12 \text { - As pessoas costumam fazer de conta que estão fazendo o trabalho de } \\
\text { forma diferente. }\end{array}$ & 1 & 2 & 3 & 4 & 5 \\
\hline $\begin{array}{l}13 \text { - A falta de informação sobre os processos de mudança gera fantasias e } \\
\text { expectativas irreais nos servidores. }\end{array}$ & 1 & 2 & 3 & 4 & 5 \\
\hline $\begin{array}{l}14 \text { - É comum mudar continuamente de direção, sem dar continuidade ao que } \\
\text { já foi feito. }\end{array}$ & 1 & 2 & 3 & 4 & 5 \\
\hline $\begin{array}{l}15 \text { - Os servidores acreditam que podem realizar mudanças no ambiente } \\
\text { organizacional. }\end{array}$ & 1 & 2 & 3 & 4 & 5 \\
\hline $\begin{array}{l}16 \text { - As pressões por mudanças nesta organização geram insatisfação nas } \\
\text { pessoas. }\end{array}$ & 1 & 2 & 3 & 4 & 5 \\
\hline $\begin{array}{l}17 \text { - As mudanças nesta organização são importantes porque trazem } \\
\text { benefícios para os servidores. }\end{array}$ & 1 & 2 & 3 & 4 & 5 \\
\hline $\begin{array}{l}18 \text { - Fazer de conta que mudou é uma característica das pessoas desta } \\
\text { organização. }\end{array}$ & 1 & 2 & 3 & 4 & 5 \\
\hline 19 - As mudanças são benéficas porque podem “oxigenar” esta organização. & 1 & 2 & 3 & 4 & 5 \\
\hline 20 - As pessoas assumem o novo discurso para se defenderem das mudanças. & 1 & 2 & 3 & 4 & 5 \\
\hline 21 - As pessoas costumam falar que a mudança aconteceu, mas na prática & 1 & 2 & 3 & 4 & 5 \\
\hline
\end{tabular}




\begin{tabular}{|c|c|c|c|c|c|}
\hline não acontece. & & & & & \\
\hline $\begin{array}{l}22 \text { - Esta organização não planeja os processos de mudança, eles } \\
\text { simplesmente acontecem. }\end{array}$ & 1 & 2 & 3 & 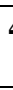 & 5 \\
\hline $\begin{array}{l}23 \text { - As mudanças nesta organização geram oportunidades para o crescimento } \\
\text { pessoal. }\end{array}$ & 1 & 2 & 3 & & 5 \\
\hline $\begin{array}{l}24 \text { - As pessoas se sentem amedrontadas pelas incertezas geradas por uma } \\
\text { nova forma de trabalhar. }\end{array}$ & 1 & 2 & 3 & & 5 \\
\hline $\begin{array}{l}25 \text { - As pessoas costumam fazer de conta que concordam com as mudanças, } \\
\text { mas não deixam que estas sejam implantadas. }\end{array}$ & 1 & 2 & 3 & & 5 \\
\hline $\begin{array}{l}26 \text { - Fazer corpo mole ao lidar com processos de mudança é uma prática } \\
\text { comum nesta organização. }\end{array}$ & 1 & 2 & 3 & & 5 \\
\hline $\begin{array}{l}27 \text { - A mudança traz a necessidade de conhecimento mais detalhado da forma } \\
\text { de funcionamento do trabalho. }\end{array}$ & 1 & 2 & 3 & & 5 \\
\hline $\begin{array}{l}28 \text { - As pessoas resistem a se aprofundar na compreensão dos propósitos da } \\
\text { mudança. }\end{array}$ & 1 & 2 & 3 & & 5 \\
\hline $\begin{array}{l}29 \text { - Os servidores que perderam posição em função da mudança geralmente } \\
\text { se opõem ao processo. }\end{array}$ & 1 & 2 & 3 & & 5 \\
\hline $\begin{array}{l}30 \text { - A falta de informação sobre os processos de mudança gera mal- } \\
\text { entendidos na organização. }\end{array}$ & 1 & 2 & 3 & & 5 \\
\hline $\begin{array}{l}31 \text { - Não permitir que todos os objetivos da mudança sejam concretizados } \\
\text { dentro do prazo é comum nesta organização. }\end{array}$ & 1 & 2 & 3 & & 5 \\
\hline $\begin{array}{l}32 \text { - As mudanças nesta organização geralmente ficam no nível do discurso, } \\
\text { não ocorrem de fato. }\end{array}$ & 1 & 2 & 3 & & 5 \\
\hline 33- Aqui as várias tentativas de mudança continuam não dando certo. & 1 & 2 & 3 & & 5 \\
\hline 34 - As pessoas mais comprometidas são mais favoráveis à mudança. & 1 & 2 & 3 & & 5 \\
\hline $\begin{array}{l}35 \text { - As mudanças comportamentais dentro desta organização, são sempre } \\
\text { muito lentas. }\end{array}$ & 1 & 2 & 3 & & 5 \\
\hline $\begin{array}{l}36 \text { - A mudança gera oportunidade para os servidores que souberem se } \\
\text { aproveitar dela. }\end{array}$ & 1 & 2 & 3 & & 5 \\
\hline
\end{tabular}

\begin{tabular}{|c|c|c|c|c|}
\hline $\begin{array}{l}37 \text { - Você concorda que a mudança na presidência da instituição afeta de } \\
\text { alguma forma o desempenho de sua unidade. }\end{array}$ & & 2 & 3 & \\
\hline $\begin{array}{l}38 \text { - Você associa os principais processos de mudança na sua unidade à } \\
\text { mudança na presidência da instituição. }\end{array}$ & 1 & 2 & 3 & 4 \\
\hline
\end{tabular}


Por fim, gostaríamos que respondesse a alguns dados relevantes para a pesquisa.

\begin{tabular}{|l|l|}
\hline Idade __ anos & Sexo mas ( ) fem ( ) \\
\hline Tempo de serviço na organização __ anos & \\
\hline
\end{tabular}

Escolaridade

\begin{tabular}{|l|l|l|}
\hline $1^{\circ}$ Grau incompleto ( ) & $2^{\circ}$ Grau completo ( ) & Especialização ( ) \\
\hline $1^{\circ}$ Grau completo ( ) & Superior incompleto ( ) & Mestrado ( ) \\
\hline $2^{\circ}$ Grau incompleto ( ) & Superior completo ( ) & Doutorado ( ) \\
\hline
\end{tabular}

\section{Cargo}

\begin{tabular}{|l|l|}
\hline Auxiliar judiciário ( ) & Requisitado ( ) \\
\hline Técnico Judiciário ( ) & Sem Vínculo ( ) \\
\hline Analista Judiciário ( ) & \\
\hline
\end{tabular}

Atualmente ocupa alguma destas funções:

\begin{tabular}{|c|c|c|}
\hline FC 01 ( ) & FC 05 ( ) & CJ 03 ( ) \\
\hline FC 02 ( ) & FC 06 ( ) & CJ 04 ( ) \\
\hline FC 03 ( ) & CJ 01 ( ) ocupa FC ( ) \\
\hline FC 04 ( ) & CJ 02 ( ) \\
\hline
\end{tabular}

